\title{
PEMBUATAN PROTOTYPE APLIKASI GAME EDUKASI SISTEM TATA SURYA UNTUK SIWA SEKOLAH DASAR
}

\author{
Herni Fajar Santi ${ }^{1)}$, Ika Asti Astuti ${ }^{2)}$ \\ 1) 2) Sistem Informasi Universitas Amikom Yogyakarta \\ email: $\underline{\text { herni.sa@students.amikom.ac.id }}{ }^{1)}, \underline{\text { asti@ amikom.ac.id }}^{2)}$
}

\begin{abstract}
Abstraksi
Pembelajaran tata surya yang dilakukan masih banyak yang menggunakan media seperti buku dan alat peraga. Media yang digunakan seperti buku dan alat peraga yang ada di sekolah biasanya perlu terus di ..... Game merupakan salah satu media yang dapat digunakan untuk pembelajaran. Model pembelajaran menggunakan game terbukti dapat membuat pembelajaran menjadi lebih aktif, efektif dan menyenangkan, sehingga meningkatkan minat belajar siswa, meningkatkan hasil belajar siswa, dan keaktifan siswa dalam mengembangkan potensi yang ada. Tujuan dari penelitian ini adalah membantu agar siswa memahami tentang sistem tata surya menggunakan prototype game yang dibuat. Metodologi penelitian yang digunakan adalah Metode Waterfall yang terdiri dari empat tahapan yaitu, Analisis Kebutuhan, Desain Sistem, Implementasi, dan Pengujian. Dengan Aplikasi Game Edukasi Sistem Tata Surya ini dapat membantu siswa belajar mandiri. Hasil dari penelitian ini yaitu bahwa prototype game yang dibuat sudah mudah digunakan oleh siswa.
\end{abstract}

Kata Kunci : sistem tata surya, metode waterfall, dan game edukasi

\begin{abstract}
There are still many learning in the solar system that uses media such as books and teaching aids. Media that is used such as books and teaching aids that are available in schools usually need to be continued ... The game is one of the media that can be used for learning. The learning model using games has been proven to make learning more active, effective and enjoyable, thus increasing student interest in learning, increasing student learning outcomes, and student activity in developing existing potential. The purpose of this research is to help students understand about the solar system using prototype games that are made. The research methodology used is the Waterfall Method which consists of four stages namely, Requirement Analysis, System Design, Implementation, and Testing. With this Solar System Educational Game Application can help students learn independently. The results of this study are that prototype games made are already easy to use by students.
\end{abstract}

Keywords : solar system, waterfall method, and education game

\section{Pendahuluan}

Ilmu pengetahuan dan kemajuan teknologi telah berkembang dengan sangat pesat. Perkembangan teknologi ini sangat bermanfaat di semua bidang. Penggunaan teknologi dalam ilmu kependidikan akan meningkatkan kualitas pendidikan yang ada [1].

Tata surya merupakan kumpulan benda langit yang mengelilingi matahari sebagai pusatnya. Bendabenda langit tersebut antara lain adalah depalan buah planet, satelit, asteroid, dan masih banyak lagi benda langit lainnya. Delapan planet itu antara lain Merkurius, Venus, Bumi, Mars, Yuppiter, Saturnus, Uranus, dan Neptunus. Materi tata surya merupakan salah satu materi pelajaran pada ilmu pengetahuan alam yang diajarkan di sekolah dasar dalam sistem pendidikan di Indonesia, tepatnya pada kurikullum 2013 hasil revisi dari kurikulum terdahulu. Dimana materi pembelajaran telah disesuaikan dengan perkembangan teknologi [2].

Dengan seiring berkembangnya teknologi saat ini, pembelajaran telah dikembangkan dengan berbagai inovasi yang berbeda antara lain: metode dalam pembelajaran, model pembelajaran, dan media pembelajaran untuk menunjang proses pembelajaran terutama untuk pembelajaran sistem tata surya. Salah satu dari inovasi pembelajaran tersebut yang dapat di manfaatkan untuk membuat suatu aplikasi game interaktif sebagai media pembelajaran sistem tata surya. Pada dasarnya game interaktif mempunyai banyak genre seperti aksi, petualangan, puzzle, simulasi, balapan, dan lain sebagainya. Dari beberapa genre tersebut, media interaktif mempunyai kelebihan untuk menjadikan proses pembelajaran lebih menarik karena tampilannya berupa teks, grafis, foto, audio, video maupun animasi sehingga proses pembelajaran terutama tentang sistem tata surya tidak membosankan [3].

Berdasarkan observasi yang peneliti lakukan, menunjukkan bahwa model awal pembelajaran yang diterapkan di SD Negeri Sukabumi masih bersifat konvensional, dimana dalam proses pembelajarannya metode ceramah sangat mendominasi. Siswa kurang berperan aktif dalam kegiatan pembelajaran dan cenderung pasif. Disamping itu, berdasarkan hasil wawancara 
kepada siswa terlihat bahwa sesungguhnya guru maupun siswa membutuhkan media pembelajaran terutama dalam bentuk multimedia interaktif yang berbasiskan komputer, agar terwujud kegiatan pembelajaran yang interaktif, efektif dan efisien. Maka dari itu berbagai teknologi dapat dimanfaatkan sebagai media pembelajaran yang dapat menyajikan visual 3D dalam pembelajaran sistem tata surya.

Berdasarkan latar belakang diatas penulis akan membuat sebuah inovasi game dengan menggabungkan visual 2D dengan 3D yang akan di kemas dalam sebuah aplikasi game edukasi yang bergenre game petualangan dan game puzzle berbasis android yang lebih menarik dan tentunya lebih imajinatif sehingga dapat digunakan sebagai media penunjang pembelajaran yang lebih interaktif bagi siswa sekolah dasar. Tujuan pembuatan game edukasi sistem tata surya ini agar siswa semangat dalam belajar baik di sekolah maupun dirumah.

\section{Tinjauan Pustaka Tata Surya}

Tata Surya merupakan sebuah sistem yang terdiri dari Matahari, delapan planet, planet-kerdil, komet, asteroid dan benda-benda angkasa kecil lain. Lintasan peredaran benda-benda langit berbentuk elips. Matahari merupakan pusat dari tata surya di mana anggota tata surya yang lain beredar mengelilingi Matahari. Ada delapan planet dalam tata surya, yaitu Merkurius, Venus, Bumi, Mars, Jupiter, Saturnus, Uranus, dan Neptunus.

\section{Media Pembelajaran}

Media pembelajaran merupakan segala sesuatu yang dapat digunakan untuk menyalurkan pesan dari pengirim ke penerima sehingga merangsang pikiran, perasaan, perhatian, dan minat serta kemauan peserta didik sehingga proses pembelajaran akan terjadi secara efektif. Penggunaan media pembelajaran yang baik dapat mendorong terjadinya proses belajar yang lebih baik [4].

\section{Game Edukasi}

Game berasal dari kata bahasa Inggris yang memiliki arti dasar Permainan. Permainan dalam hal ini merujuk pada pengertian "kelincahan intelektual" (intellectual playability). Game diartikan sebagai arena keputusan dan aksi pemainnya. Game atau permainan juga bisa diartikan sesuatu yang dapat dimainkan dengan aturan tertentu sehingga ada yang menang dan ada yang kalah, biasanya dalam konteks tidak serius dengan tujuan refreshing. Bermain game sudah dapat dikatakan sebagai life style masyarakat dimasa sekarang. Dimulai dari usia anak-anak sampai orang dewasa menyukai video game karena permainan video game adalah hal yang menyenangkan [5].

\section{Adobe Illustrator}

Adobe Illustrator diciptakan pada tahun 1986 dan dirancang untuk bekerja dengan komputer Macintosh. Adobe Illustrator adalah salah satu program untuk merubah gambar bitmap menjadi vector, selain merubah gambar bitmap menjadi vector, Adobe Illustrator pun dapat membuat gambar lain seperti membuat logo perusahaan dan gambar desain lainnya. Adobe Illustrator juga bisa diartikan sebuah program perangkat lunak atau program graphic design pengolah image berbasis vector. Vector itu sendiri merupakan sekumpulan titik dan garis yang saling terhubung yang merupakan perpaduan dari warna-warna sehingga membentuk sebuah objek menggambar yang diciptakan oleh Adobe System yang menggunakan vector [6].

\section{Unity}

Unity adalah game engine buatan Unity Technologies Inc. Setelah mengalami masa pengembangan selama 4 tahun, pada tahun 2005 Unity pertama kali diluncurkan. Unity merupakan sebuah tools yang terintegrasi untuk membuat bentuk objek tiga dimensi pada video game atau konten interaktif lain seperti Visualisasi Arsitektur atau animasi 3D real-time. Aplikasi yang dibuat oleh Unity dapat berjalan pada Windows, Mac, Xbox 360, Playstation 3, Wii, iPad, iPhone dan juga platform Android. Unity juga merupakan suatu aplikasi yang digunakan untuk mengembangkan game multiplatform yang didesain untuk mudah digunakan [7].

\section{Metode Penelitian}

Metode yang digunakan untuk merancang dan membuat game edukasi ini adalah dengan metode waterfall yang memiliki tahapan-tahapan seperti pada Gambar 1.

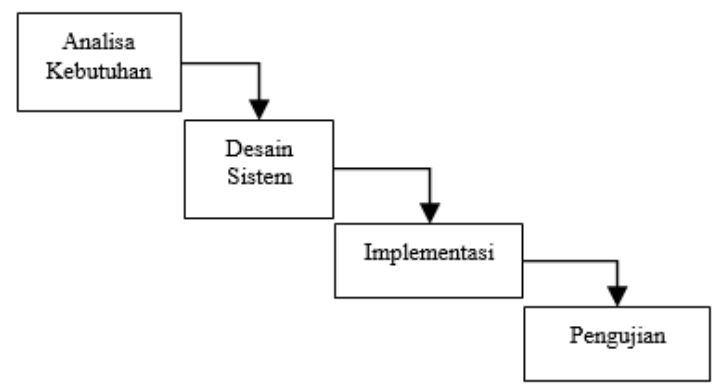

Gambar 1. Metode Waterfall

Berikut keterangan dari tahapan-tahapan dari metode yang digunakan: 


\section{A. Analisis Kebutuhan}

Tahapan ini dilakukan untuk menganalisis kebutuhan yang akan digunakan untuk merancang dan membuat game edukasi tata surya, dimulai dengan menentukan tema, judul game, dan platform yang akan digunakan. Adapun alat-alat yang digunakan meliputi hardware dan software yang terdiri dari:

a. Hardware

1. Laptop Lenovo iCore 3 64bit.

2. Smartphone android.

b. Software

1. Unity

2. Adobe Illustrator 2019

3. Adobe Audition 2019

\section{B. Desain Sistem}

Setelah analisis kebutuhan dilakukan dan kebutuhan sudah terpenuhi secara lengkap maka penulis harus melakukan perancangan desain yang akan diterapkan dalam game yang dibuat meliputi Use Case Diagram, Storyboard, Background dan Audio/Sound.

[1] Use case diagram

Diagram use case ini menjelaskan dan menerangkan perilaku yang diinginkan oleh pengguna. Dalam aplikasi ini user dapat melakukan perilaku yaitu memilih menu seperti, dua menu main yaitu jelajah dan puzzle, menu tentang, dan menu setting.

[2] Storyboard

Tahapan ini dilakukan pembuatan storyboard yang merupakan gambaran dari alur game yang akan dibuat.

[3] Background dan Audio Sound

Selain merancang storyboard penulis juga menyiapkan sound dan background yang akan digunakan di dalam game harus sesuai seperti sedang berada di luar angkasa. Selain itu juga terdapat sound effect yang digunakan ketika roket terkena meteor dan bintang.

\section{Implementasi}

Tahap ini game dibuat berdasarkan kebutuhan dan sesuai dengan design yang telah ada. Kemudian game dibuat dengan menggunakan Unity.

\section{Pengujian}

Setelah game selesai dibuat, penulis melakukan pengujian ke beberapa platform seperti laptop dan smartphone android. Pengujian dilakukan menggunakan metode black box untuk mengetahui apakah game dapat berjalan tanpa ada kesalahan. Pengujian metode usability atau System Usability Scale (SUS) juga dilakukan dengan mengujikan game dan memberikan kuisoner kepada 25 siswa di SD Negeri Sukabumi.

\section{Hasil dan Pembahasan}

Penelitian ini menghasilkan sebuah game edukasi tentang tata surya yang dapat membantu proses pembelajaran pada siswa sekolah dasar. Game ini dibuat dengan menggunakan Unity dan dapat diaplikasikan di beberapa platform seperti android, $i O S$, dan web. Berikut adalah pembahasan hasil dari penelitian yang telah penulis lakukan:

A. Hasil Tampilan

a. Halaman splash menu/ menu loading

Terdapat tampilan loading pada awal game.

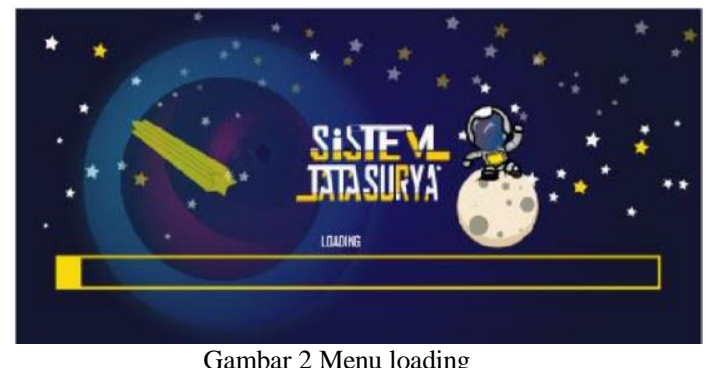

b. Halaman menu utama

Setelah tampilan loading maka akan masuk ke tampilan menu utama dari game "Sistem Tata Surya".

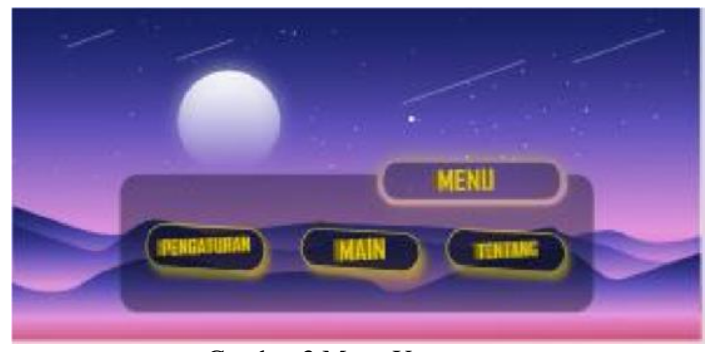

Gambar 3 Menu Utama

c. Halaman menu tentang

Halaman ini berisi informasi tentang game tata surya yang dibuat.

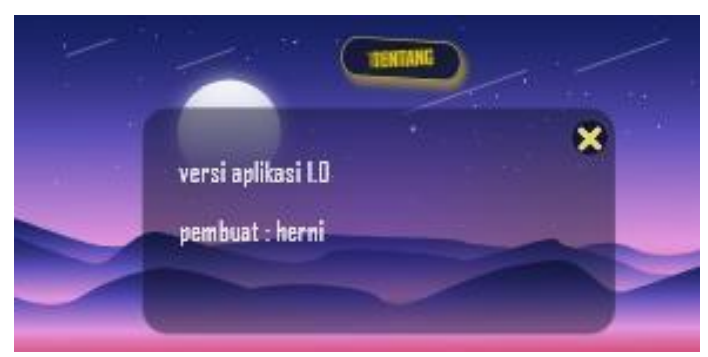

Gambar 4 Menu Tentang

d. Halaman menu Pengaturan

Halaman ini user bisa mengubah atau mengatur music dan sound untuk bermain game tata surya ini. 


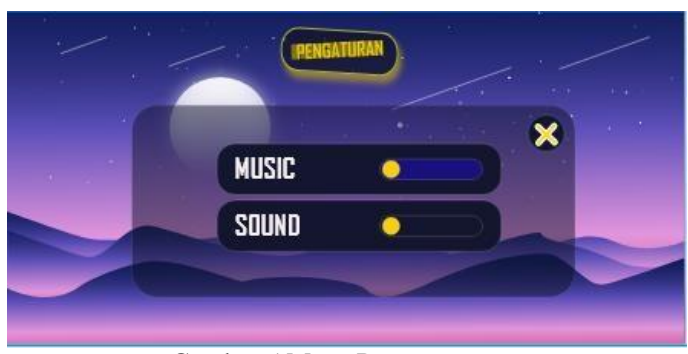

Gambar 5 Menu Pengaturan.

e. Halaman menu main

Dalam menu main ini terdiri dari 2 sub menu main yaitu menu jelajah dan menu puzzle.

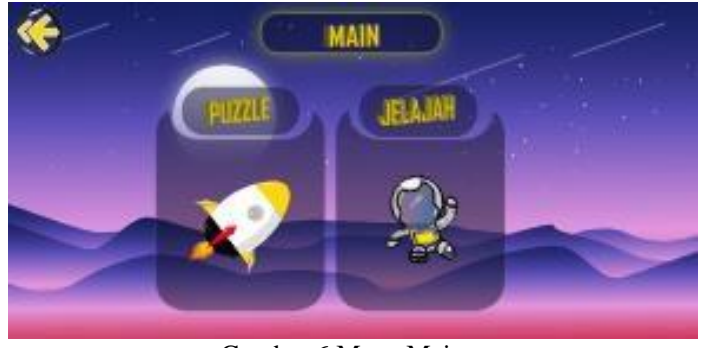

Gambar 6 Menu Main.

f. Halaman menu main jelajah Halaman main jelajah ini user nantinya bisa memilih objek jelajah yang akan dituju. Dimana pilihaan objek nya ialah bagian dari tata surya, lalu selama berjelajah menuju objek yang dituju akan mengalami berbagai gangguan seperti kejatuhan meteor atau bintang. Dimana user harus bisa menghindarinya agar nyawa tidak habis. Dan jika user berhasil maka user nantinya bisa melihat informasi tentang planet tata surya yang dituju.

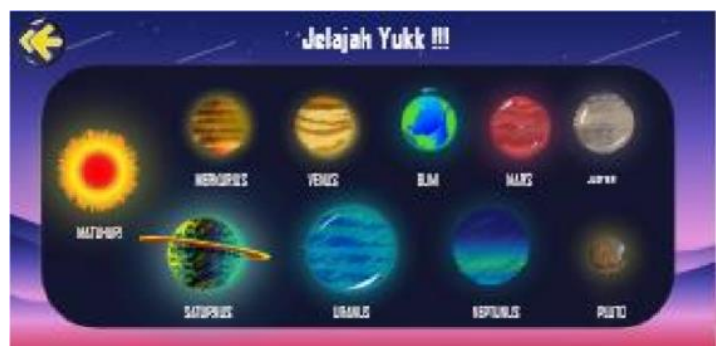

Gambar 7 Menu jelajah

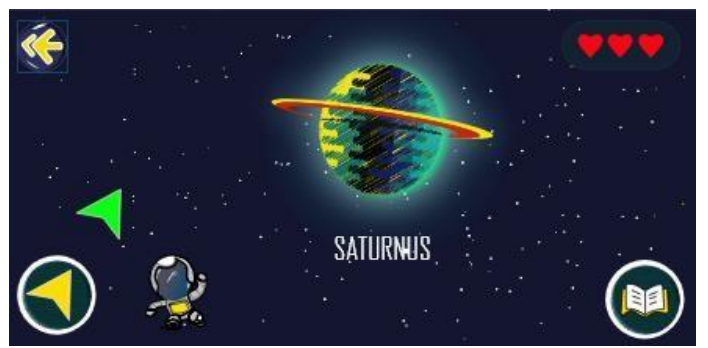

Gambar 8 Menu Main Jelajah

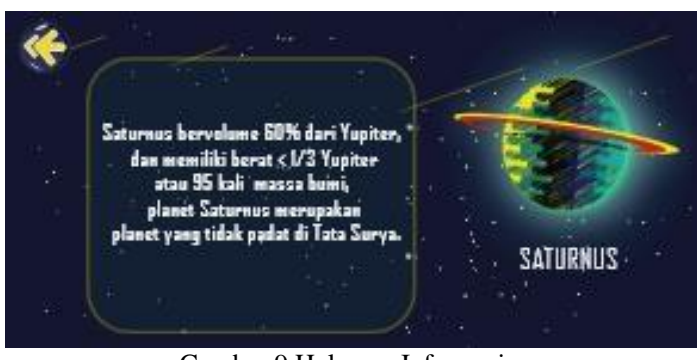

Gambar 9 Halaman Informasi

g. Halaman game puzzle

Hampir sama dengan game jelajah dimana user memilih objek terlebih dahulu dan seperti game puzzle pada umumnya dimana user bisa menyusun pecahan objek menjadi objek yang sempurna.

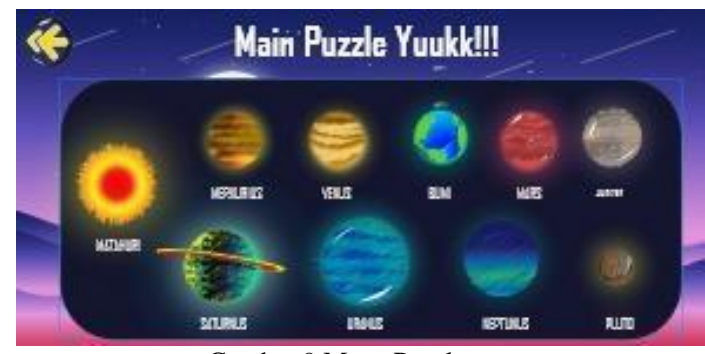

Gambar 9 Menu Puzzle.

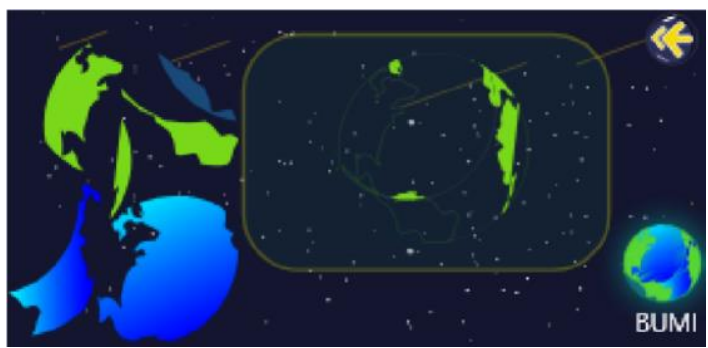

Gambar 10 Halaman Main Puzzle

\section{B. Pengujian}

Pengujian dilakukan dengan melakukan pengenalan game dan dilanjutkan dengan pelatihan menggunakan game. Setelah menggunakan game, user diminta untuk mengisi sebuah kuisoner. Pertanyaan yang digunakan dalam kuesioner diambil dari kuesioner SUS (System Usability Scale) yang terdiri dari 10 pernyataan.

Tabel 1 Hasil jumlah skor dan presentase kuesioner SUS

\begin{tabular}{|l|l|c|c|}
\hline $\begin{array}{l}\text { Indikat } \\
\text { or }\end{array}$ & Elemen kepuasan & $\sum$ Skor & Presentase\% \\
\hline 1 & $\begin{array}{l}\text { Saya ingin sering } \\
\text { menggunakan sistem } \\
\text { ini }\end{array}$ & 97 & 77,6 \\
\hline 2 & $\begin{array}{l}\text { Sistem/aplikasi yang } \\
\text { dibuat tidak rumit }\end{array}$ & 108 & 86,4 \\
\hline 3 & $\begin{array}{l}\text { Sistem yang dibuat } \\
\text { mudah digunakan }\end{array}$ & 113 & 90,4 \\
\hline 4 & $\begin{array}{l}\text { Saya memerlukan } \\
\text { bantuan orang lain } \\
\text { untuk menggunakan } \\
\text { system/aplikasi yang } \\
\text { dibuat }\end{array}$ & 69 & 55,2 \\
\hline 5 & $\begin{array}{l}\text { Berbagai fungsi dalam } \\
\text { sistem ini terintegrasi }\end{array}$ & 87 & 69,6 \\
\hline
\end{tabular}




\begin{tabular}{|l|l|c|c|}
\hline & dengan baik. & & \\
\hline 6 & $\begin{array}{l}\text { Saya pikir ada terlalu } \\
\text { banyak } \\
\text { ketidakkonsistenan } \\
\text { dalam sistem ini. }\end{array}$ & 54,2 \\
\hline 7 & $\begin{array}{l}\text { Kebanyakan orang } \\
\text { akan cepat memahami } \\
\text { cara kerja } \\
\text { system/aplikasi ini }\end{array}$ & 83 & 66,4 \\
\hline 8 & $\begin{array}{l}\text { Sistem ini rumit untuk } \\
\text { digunakan }\end{array}$ & 66 & 52,8 \\
\hline 9 & $\begin{array}{l}\text { Saya sangat percaya } \\
\text { diri dalam } \\
\text { menggunakan } \\
\text { aplikasi/sistem bem }\end{array}$ & 80 & 64 \\
\hline 10 & $\begin{array}{l}\text { Saya perlu belajar } \\
\text { banyak hal untuk bisa } \\
\text { menggunakan } \\
\text { system/aplikasi ini. }\end{array}$ & 58 & 46,4 \\
\hline
\end{tabular}

Berdasarkan Gambar 10 presentase nilai tertinggi yaitu sebesar 90,4\% diperoleh pada pernyataan ke tiga bahwa prototype system yang dibuat mudah digunakan. Sedangkan presentase terendah terletak pada pernyataan ke enam yang menyatakan bahwa prototype system yang dibuat memiliki banyak ketidakkonsistenan.

\section{Kesimpulan dan Saran}

Berdasarkan pengujian SUS (System Usability Scale) diperoleh kesimpulan bahwa prototype system yang dibuat sudah dapat memenuhi kemudahan pengguna namun, kelemahan dalam prototype yang dibuat yaitu dinilai masih terdapat ketidakkonsistenan.

Adapun saran yang diberikan yaitu dengan memperbaiki ketidakkonsistenan yang dimaksud dengan penyamaan button-button yang digunakan atau fitur-fitur lainnya untuk melakukan penambahan data mengenai tata surya. Kedepannya prototype dapat diimplementasikan menjadi sebuah aplikasi nyata.

\section{Daftar Pustaka}

[1] R. Bangun, M. Pengenalan, and S. Tata, "Rancang Bangun Media Pengenalan Susunan Tata Surya," vol. 7, no. 2, pp. 52-59, 2014.

[2] P. Ilmiah, "GAME EDUKASI MEMPELAJARI SISTEM TATA SURYA UNTUK MURID KELAS VI DI SDIT NUR HIDAYAH SURAKARTA,” 2019.

[3] I. K. Alit, M. Wiguna, I. G. M. Darmawiguna, and I. M. Putrama, "Pengembangan Aplikasi Game The Adventure Of Lubdhaka Berbasis Android," no. Senapati, 2016.

[4] H. Dan, K. Hidrolik, and S. Smk, "PENGEMBANGAN MEDIA PEMBELAJARAN GAME EDUKASI UNTUK BELAJAR MANDIRI PADA KOMPETENSI DASAR EDUCATION GAME DEVELOPMENT AS SELF LEARNING MEDIA IN BASIC," no. 2, pp. 87-95.

[5] D. I. S. M. P. N. Yogyakarta and A. Putranto, "PENGEMBANGAN GAME EDUKASI KLASIFIKASI HEWAN MENGGUNAKAN ADOBE
FLASH PROFESSIONAL CS5 SEBAGAI MEDIA PEMBELAJARAN BIOLOGI KELAS VII.”

[6] F. Novitasari, Y. Djahir, and S. Fatimah, "PENGARUH MEDIA ADOBE ILLUSTRATOR TERHADAP HASIL BELAJAR PESERTA DIDIK PADA MATA PELAJARAN EKONOMI DI SMA SRIJAYA NEGARA."

[7] A. D. E. Randi, Oleh : 2017. 